\title{
Storm effects on intertidal invertebrates: increased beta diversity of few individuals and species
}

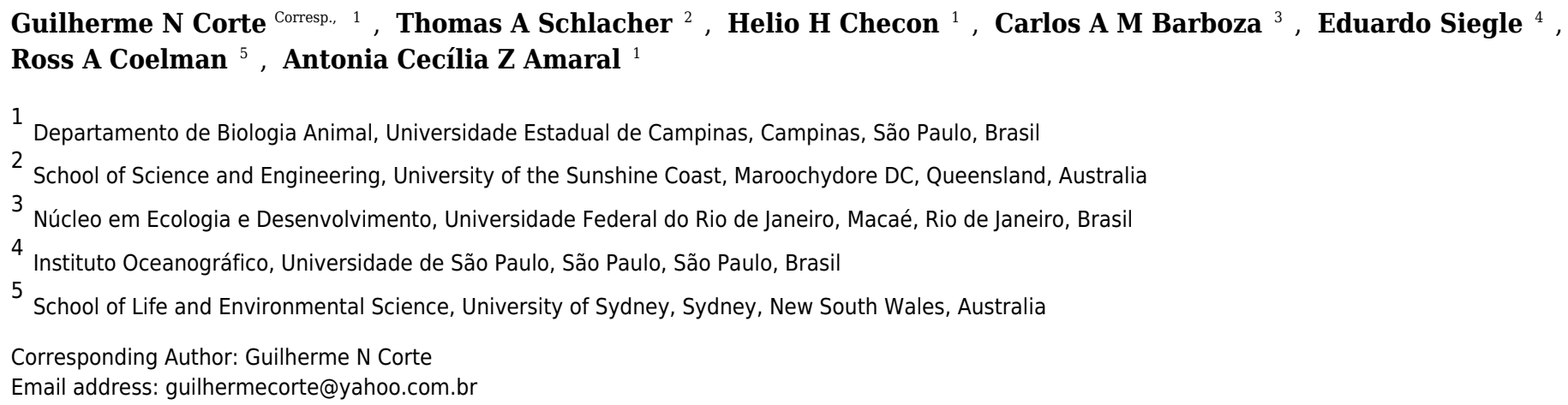

Climate change is predicted to lead to more extreme weather events, including changes to storm frequency, intensity and location. Yet, the ecological responses to storms are incompletely understood for sandy shorelines, the globe's longest land-ocean interface. Here we document how storms of different magnitude impacted the invertebrate assemblages on a tidal flat in Brazil. We specifically tested the relationships between wave energy and spatial heterogeneity, both for habitat properties (habitat heterogeneity) and fauna ( $\beta$-diversity), predicting that larger storms redistribute sediments and hence lead to spatially less variable faunal assemblages. The sediment matrix tended to become less heterogeneous across the flat after high-energy wave events, whereas $\beta$-diversity increased after storms. This higher $\beta$-diversity was primarily driven by species losses. Significantly fewer species at a significantly lower density occurred within days to weeks after storms. Negative density and biomass responses to storm events were most prominent in crustaceans. Invertebrate assemblages appeared to recover within a short time (weeks to months) after storms, highlighting that most species typical of sedimentary shorelines are, to some degree, resilient to short-term changes in wave energy. Given that storm frequency and intensity are predicted to change in the coming decades, identifying properties that determine resilience and recovery of ecosystems constitute a research priority for sedimentary shorelines and beyond. 
1 Storm effects on intertidal invertebrates: increased beta diversity of few individuals and

2 species

4 Short title: Storm effects on intertidal invertebrates

5

6 Guilherme N. Corte ${ }^{1 \S^{*}}$, Thomas A. Schlacher $2 \S$, Helio H. Checon¹, Carlos A. M. Barboza ${ }^{3}$, Eduardo

7 Siegle $^{4}$, Ross A. Coleman ${ }^{5}$, A. Cecilia Z. Amaral ${ }^{1}$

8

9 1Departamento de Biologia Animal, Universidade Estadual de Campinas (UNICAMP), CEP 13083-862, Campinas,

${ }^{2}$ School of Science and Engineering, University of the Sunshine Coast, Maroochydore DC, QLD 4558, Australia. tschlach@usc.edu.au

${ }^{3}$ Núcleo em Ecologia e Desenvolvimento, Universidade Federal do Rio de Janeiro, CEP, 27965-045Macaé, RJ. carlosambarboza@gmail.com

${ }^{4}$ Instituto Oceanográfico, Universidade de São Paulo (USP), CEP 05508-120 São Paulo, SP, Brazil. esiegle@usp.br ${ }^{5}$ Coastal \& Marine Ecosystems, School of Life and Environmental Science, The University of Sydney, NSW 2006, Australia. ross.coleman@sydney.edu.au

$\S$ both authors contributed equally to this work

${ }^{*}$ Corresponding author: guilhermecorte@yahoo.com.br 


\section{Abstract}

27

Climate change is predicted to lead to more extreme weather events, including changes to storm frequency, intensity and location. Yet, the ecological responses to storms are incompletely understood for sandy shorelines, the globe's longest land-ocean interface. Here we document how storms of different magnitude impacted the invertebrate assemblages on a tidal flat in Brazil. We specifically tested the relationships between wave energy and spatial heterogeneity, both for habitat properties (habitat heterogeneity) and fauna ( $\beta$-diversity), predicting that larger storms redistribute sediments and hence lead to spatially less variable faunal assemblages. The sediment matrix tended to become less heterogeneous across the flat after high-energy wave events, whereas $\beta$-diversity increased after storms. This higher $\beta$-diversity was primarily driven by species losses. Significantly fewer species at a significantly lower density occurred within days to weeks after storms. Negative density and biomass responses to storm events were most prominent in crustaceans. Invertebrate assemblages appeared to recover within a short time (weeks to months) after storms, highlighting that most species typical of sedimentary shorelines are, to some degree, resilient to short-term changes in wave energy. Given that storm frequency and intensity are predicted to change in the coming decades, identifying properties that determine resilience and recovery of ecosystems constitute a research priority for sedimentary shorelines and beyond. 


\section{1. Introduction}

48

Extreme weather events, including changes to storm frequency and intensity, are predicted to increase over the $21^{\text {st }}$ century (IPCC 2013, Lin and Emanuel 2016, Walsh et al. 2016). These global changes to ecosystem physical and chemical conditions are having numerous and widespread biological impacts in the sea and on land (Weatherdon et al. 2016). In the global oceans, climate change is expected to substantially alter the provision of ecosystems services critical to humankind, such as coastal protection and capture fisheries (Gattuso et al. 2015), but many responses in marine ecoystems still remain incompletely understood (Hauser et al. 2016, Nagelkerken and Munday 2016).

Storms may cause massive changes to coastal environments, particularly on sedimentary shorelines (Mateo and Garcia-Rubies 2012), often causing the translocation of sediment from the beach and dunes, and the landwards movement of the coastline (Masselink et al. 2016). These large habitat changes are usually accompanied by impacts to faunal assemblages, best documented for benthic invertebrates, seagrass meadows, and algal communities (Lucrezi et al. 2010, Jaramillo et al. 2012, Mateo and GarciaRubies 2012).

The unpredictable nature of storms generally precludes the use of a rigorous experimental design to specifically test for storm effects, meaning that nearly all published 'storm studies' are largely opportunistic (Harris et al. 2011). In addition, often only a few or no data points are available immediately before a storm, post-storm sampling can be truncated, and for large storms it is challenging or impossible to find control areas that were not affected by the event (Posey et al. 1996); arguably, this makes attribution of ecological patterns to storm effects somewhat weak. An alternative is to make a priori predictive hypotheses based on knowledge of the biology of species and their likely response to large disturbance events in their habitat (Harris et al. 2011).

Here, we combine oceanographic, sedimentary and biological data to investigate how storms can affect the sedimentary habitat of a tidal flat in Southeast Brazil and the macrobenthic assemblages inhabiting it. Specifically, we tested four complementary, predictive hypotheses:

1. Higher wave energy during storms may translocate and disperse large sediment volumes (Masselink et al. 2016). We therefore predict that habitat heterogeneity (i.e. the spatial variation in seafloor properties amongst sampling sites) would be reduced after storms.

2. Habitat heterogeneity can be a major determinant for ecological assemblages, typically promoting beta diversity (i.e. variability in species composition among sampling units for a given area) 
83

84

85

86

87

88

89

90

91

92

93

94

95

96

97

98

99

100

101

102

103

104

105

106

(Anderson et al. 2006, Schlacher et al 2007, McClain and Barry 2010, Meager et al. 2011).

Therefore, we expect that storms lower beta diversity of the fauna.

3. Disturbance caused by storms has been reported to detrimentally affect populations of benthic species (Jaramillo et al. 1987, Mateo and Garcia-Rubies 2012). Accordingly, we expect lower species richness, abundance, and biomass of invertebrates after storms.

4. Given that we expect lower $\beta$-diversity (prediction 2 ) and reduced number of species after storms (prediction 3 ), we predict that changes in $\beta$-diversity may be mainly attributable to species losses rather than species replacement.

\section{Material and Methods}

\subsection{Study area}

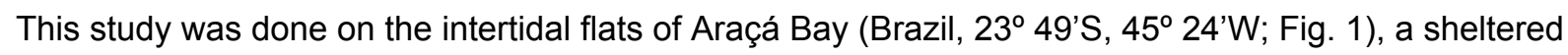
and heterogeneous intertidal flat adjacent to the São Sebastião Channel, Southeast Brazil (Amaral et al. 2010). The area is relatively small (ca. $750 \mathrm{~m}$ wide and long) and protected from the prevailing swell by São Sebastião Island (Fig. 1). It is one of few tide-dominated environments along the southeastern coast of Brazil (Dottori et al. 2015). Hydrographic properties of Araçá Bay are subject to physical forcing by frontal systems, when current speeds can increase eightfold (Fo 1990). At the region, the highest storm waves are associated to cold fronts and reaching offshore significant wave heights of $6.4 \mathrm{~m}$ (Pianca et al.2010).
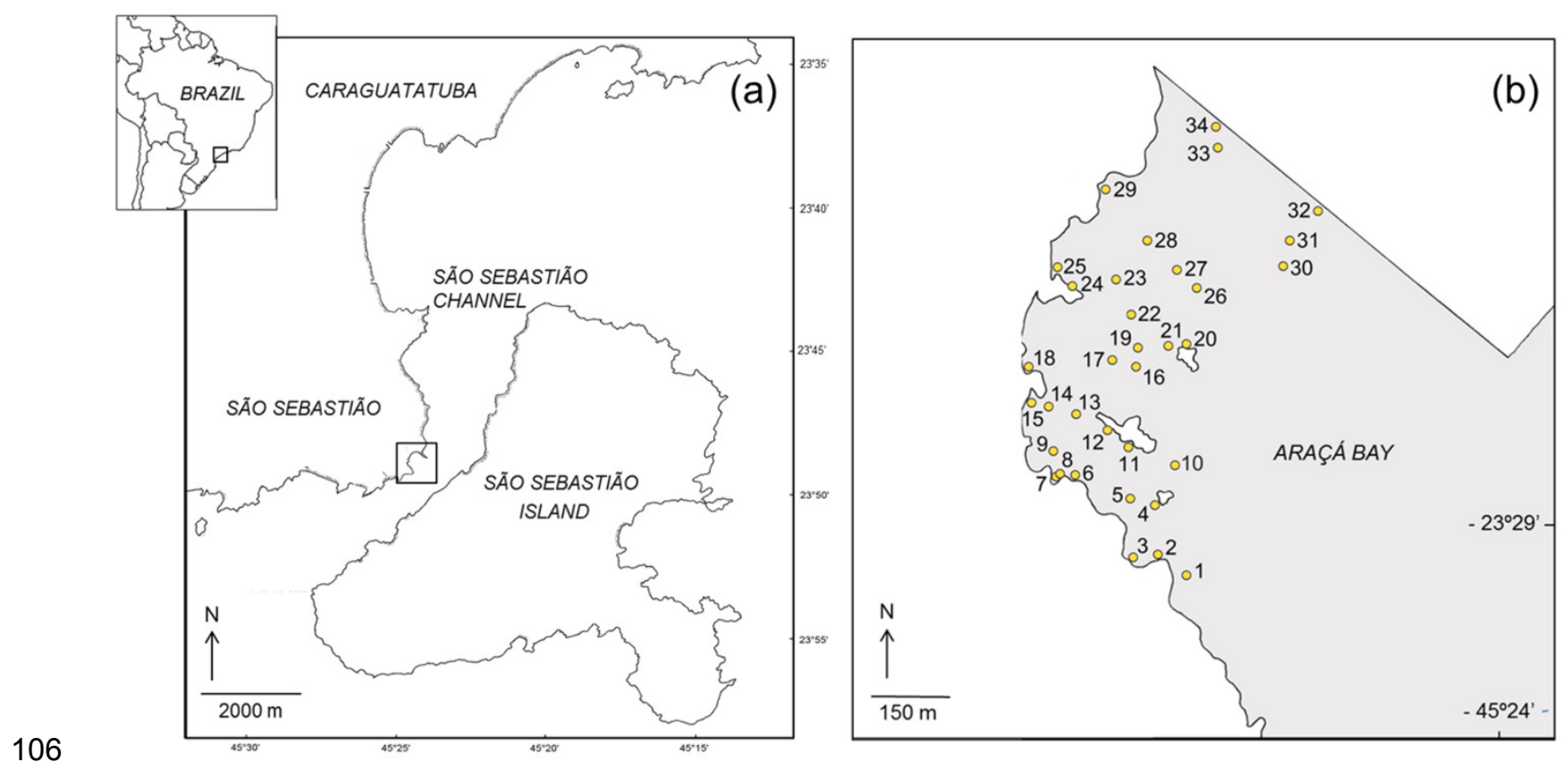
107

108

109

110

111

112

113

114

115

116

117

118

119

120

121

122

123

124

125

126

127

128

129

130

131

132

133

134

135

136

137

138

139

140

141

142

143

Fig. 1 Map showing the location of the study area (a) and the sampling sites in the intertidal area of Araçá Bay (b).

\subsection{Field sampling}

Field work was done during spring tides on four times, at ca. three month intervals, from September 2011 to July 2012 (25 September 2011, 5 February 2012, 7 May 2012, and 29 July 2012). Three storm events occurred during the study (22 November 2011, 06 May 2012, 18 July 2012; Fig. 2), all accompanied by torrential rain, strong winds, flooding, and building damages. We sampled on the first spring tide after the storms in May and July 2012 (one-day lag in May and 11 days in July).

During each sampling event, field work was done early in the morning of two consecutive days, collecting fauna from 34 sites. The sampling sites were positioned to encompass habitat diversity of the tidal flat (i.e. different sediment types over a range of depths), and to achieve a reasonable dispersion and spatial coverage (Fig. 1). The position of each sampling site was recorded with a GPS (Garmin eTrex Legend, datum WGS84) and the same locations (+/- $1 \mathrm{~m}$ ) were sampled during each of the four sampling events. Three faunal samples (corer: $20 \mathrm{~cm}$ inner diameter, $20 \mathrm{~cm}$ depth) and one sediment sample (corer: $3 \mathrm{~cm}$ inner diameter, $20 \mathrm{~cm}$ deep) were collected per site and event.

\subsection{Biological and environmental data}

Fauna cores were washed on the same day of collection through a $0.3 \mathrm{~mm}$ mesh sieve, and the retained fauna was fixed in $70 \%$ ethanol. Sediment granulometric analysis was performed with standard dry sieving described by Suguio (1973). Sediment statistics were calculated with SysGran software (Camargo 2006) using the parameters of Folk and Ward (1957). Organic matter content was determined by weight losses of dried samples $\left(60^{\circ} \mathrm{C}\right.$ for $\left.24 \mathrm{~h}\right)$ after incineration $\left(550^{\circ} \mathrm{C}\right.$ for $\left.6 \mathrm{~h}\right)$. Calcium carbonate content was determined by $10 \% \mathrm{HCl}$ digestion.

Sediment temperature and interstitial water salinity were measured in situ with a digital thermometer and an analog refractometer (precision of 0.01 and 0.1 units, respectively). Wave height and period for the region were obtained for $24.5 \mathrm{~S}$ and $45.5 \mathrm{~W}$ from the global wave generation model WaveWatch III (NCEP/NOAA). Wave power $\left(P_{w}\right)$ was calculated as: $P_{w}=\rho g^{2} H^{2} T / 32 \pi$, where $\rho$ is water density $(1,027$ $\left.\mathrm{kg} / \mathrm{m}^{3}\right), \mathrm{g}$ the acceleration due to gravity $\left(9.81 \mathrm{~m} / \mathrm{s}^{2}\right), \mathrm{H}$ the wave height $(\mathrm{m})$, and $\mathrm{T}$ the wave period (s) (Herbich 2000). We considered wave height and power for the three days before each sampling event. This time lag was found to show the strongest correlation between wave height/power and changes in macrobenthic species in the area (Turra et al. 2016).

All work was done in accordance with permit No. 19887-1 issued by the federal environmental agency, Ministério do Meio Ambiente, Instituto Chico Mendes de Conservação da Biodiversidade (ICM-Bio). 


\subsection{Data analysis}

We tested for differences in habitat heterogeneity and fauna $\beta$-diversity amongst times with permutational analysis of multivariate dispersion (PERMDISP, Anderson 2006). In this analysis, higher multivariate dispersion is an indication of higher variability (i.e., higher habitat heterogeneity and $\beta$-diversity) among sampling sites (Anderson 2006). For habitat heterogeneity, the test was based on Euclidean distances calculated from normalized sediment data. For fauna $\beta$-diversity, the test was based on Hellinger transformation (Legendre and De Cáceres 2013) calculated from abundance data for the full suite of species. PERMDISP analysis was done using Primer 6 software (Clarke and Gorley 2006). Ordination plots (nMDS) were computed with the vegan package in $R$ (Oksanen 2017) to illustrate differences in habitat heterogeneity and $\beta$-diversity (i.e. dispersion of sampling sites) between sampling events.

We tested for differences in species richness, abundance and biomass of invertebrate assemblages amongst times using general linear models with 'Time' as fixed factors. Models were adjusted using the negative binomial distributions for count data (species richness and abundance) and gamma distributions for continuous data (biomass). We used Tukey post-hoc tests to examine differences among sampling times using the MASS package in R (Ripley et al. 2013). This framework was used to investigate differences in the whole assemblage and also in the main groups of intertidal macrofauna (i.e., molluscs, polychaetes and crustaceans) separately.

We used the Similarity percentage analysis (SIMPER) based on Bray-Curtis distance to investigate the contribution of each individual species to the differences in species assemblages among sampling periods. Data was $\log (\mathrm{x}+1)$ transformed before analysis to reduce influence of abundant species. SIMPER was done in Primer 6 software (Clarke and Gorley 2006).

We used the $\beta$-diversity partitioning framework of Podani and Schmera( 2011) and Carvalho et al. (2012) to investigate compositional changes of macrobenthos (i.e. $\beta$-diversity) over time. This framework calculates compositional differences among communities $\left(\beta_{\text {total }}\right)$ and partitions it into $\beta$ diversity attributed to species replacement $\left(\beta_{\text {repl }}\right)$ and $\beta$ diversity attributed to species loss or gain $\left(\beta_{\text {rich }}\right)$. This analysis was done with the R package BAT (Cardoso et al. 2015)

\section{Results}

Seawater temperature varied seasonally, whereas salinity and organic matter content of the sediment changed relatively little over time (Table 1). The silt-, clay-, and fine sand fraction of the sediment increased between Sep. 2011 and July 2012 (Table 1). Waves were higher and more powerful before samplings in May and July 2012 (Table 1, Fig. 2). 
180

181 Table 1. Environmental parameters recorded.

\begin{tabular}{lcccc}
\hline & $\begin{array}{c}\text { September } \\
\mathbf{2 0 1 1}\end{array}$ & $\begin{array}{c}\text { February } \\
\mathbf{2 0 1 2}\end{array}$ & $\begin{array}{c}\text { May } \\
\mathbf{2 0 1 2}\end{array}$ & $\begin{array}{c}\text { July } \\
\mathbf{2 0 1 2}\end{array}$ \\
\hline & mean (se) & mean (se) & mean (se) & mean (se) \\
Temperature $\left({ }^{\circ} \mathrm{C}\right)$ & $21.9(0.2)$ & $27.4(0.2)$ & $25.0(0.2)$ & $20.4(0.1)$ \\
Salinity & $32.3(0.3)$ & $31.7(0.9)$ & $30.6(0.7)$ & $29.9(0.6)$ \\
Mean grain size $(\phi)$ & $2.5(0.7)$ & $2.7(0.7)$ & $2.7(0.5)$ & $2.8(0.64)$ \\
Silt and clay $(\%)$ & $4.2(0.6)$ & $4.7(0.6)$ & $4.8(0.6)$ & $5.7(0.9)$ \\
Fine sand $(\%)$ & $68.4(3.2)$ & $73.5(3.2)$ & $74.1(3.8)$ & $74.7(3.1)$ \\
Coarse sand $(\%)$ & $10.7(1.6)$ & $9.5(1.7)$ & $7.9(1.3)$ & $7.3(1.6)$ \\
Pebbles $(\%)$ & $6.2(1.4)$ & $3.7(1.1)$ & $3.2(0.9)$ & $3.2(1.0)$ \\
Organic matter $(\%)$ & $1.6(0.1)$ & $1.7(0.2)$ & $1.7(0.2)$ & $1.9(0.2)$ \\
CaCO $(\%)$ & $4.9(0.4)$ & $4.4(0.4)$ & $3.8(0.5)$ & $3.5(0.3)$ \\
Height of waves $(\mathrm{m})$ & $1.5(0.06)$ & $1.6(0.04)$ & $2.1(0.11)$ & $1.7(0.04)$ \\
Power of waves $\left(10^{4} \mathrm{~W} / \mathrm{s}\right)$ & $20.1(1.7)$ & $18.1(7.3)$ & $42.8(5.3)$ & $30.4(3.4)$ \\
\hline
\end{tabular}

182 

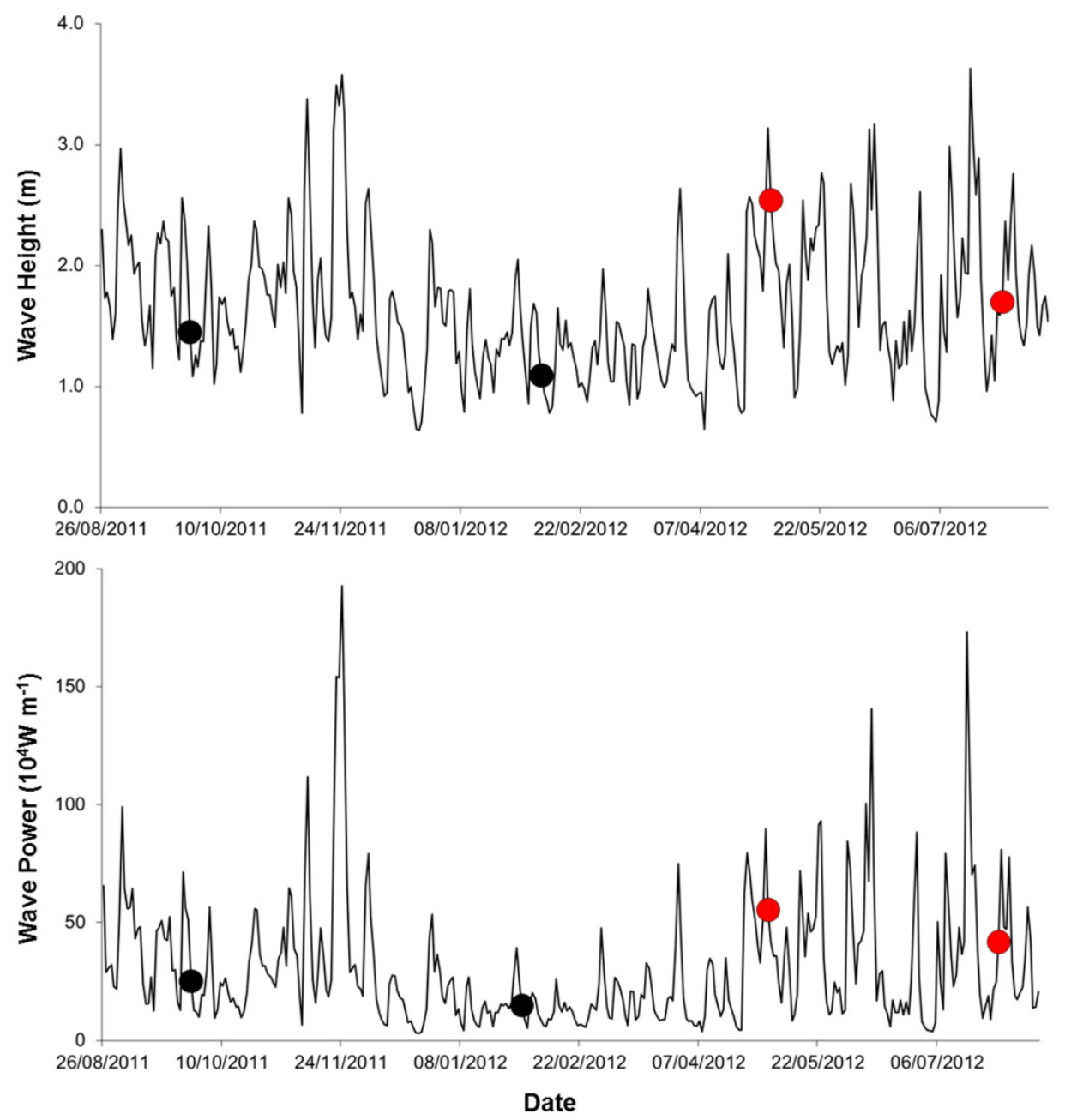

183

184

185

186

187

188

189

190

191

192

193

194

195
Fig. 2 Wave height (a) and wave power (b) during the study period (sampling events are shown by dots. Red dots correspond to storm sampling events).

We recorded 126 species from 33,320 individuals during the study (supplementary data). Polychaetes, molluscs and crustaceans made up 94\% of species (polychaetes: 67 species; molluscs: 34 species; crustaceans: 18 species). Crustaceans were the most abundant group, comprising $56.5 \%$ of all individuals, mainly because of the high number of the tanaidacean Monokalliapseudes schubartti (MañéGarzón, 1949); polychaetes made up 39.6\%, and molluscs 3.7\% of catches (supplementary data).

\section{H1: Lower habitat heterogeneity after storms}

Sediment properties were spatially more homogeneous after periods of higher wave power (Fig. 3a), but differences between sampling times were not significant (Fig. 4a; PERMDISP $P=0.586$ ). 

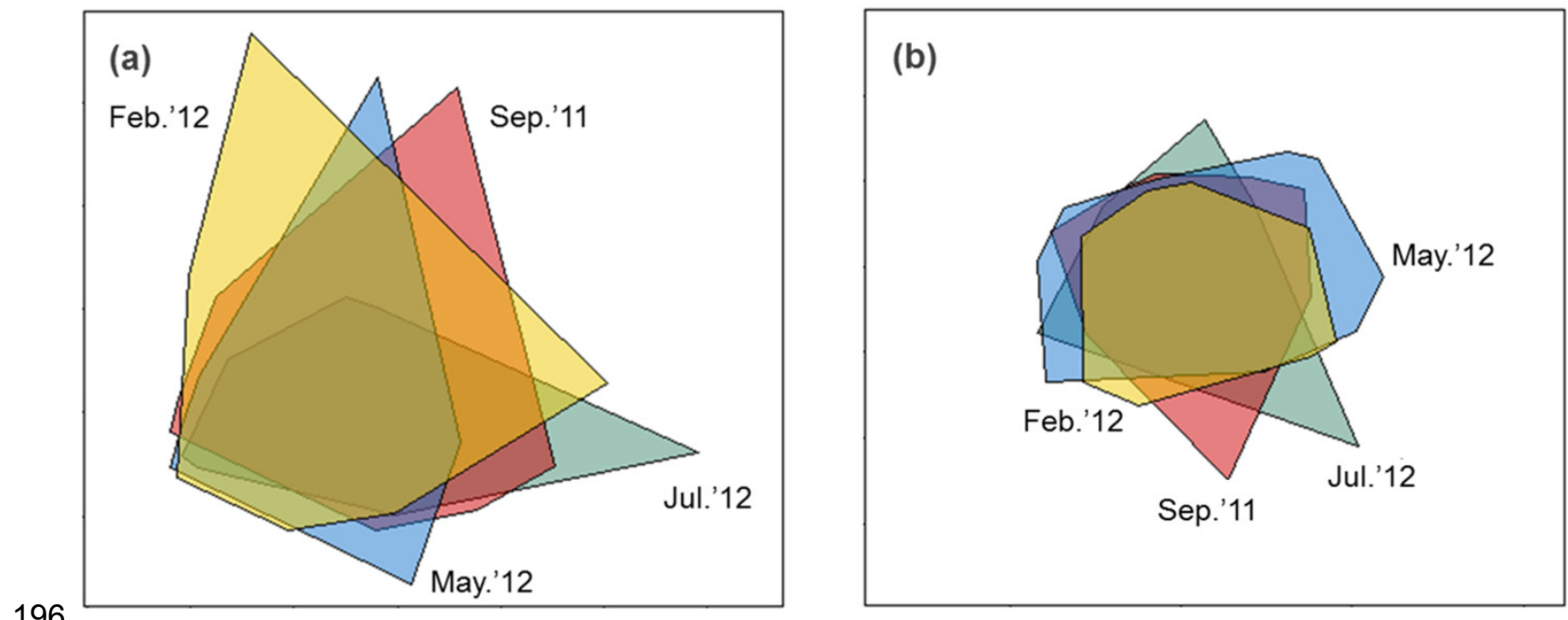

Fig. 3 nMDS biplot of Euclidean distance based normalized environmental data (a) and nMDS biplot of Hellinger disimilarity matrix based on macrobenthic abundance data (b). Samples from September 2011 are located inside the polygon plotted in red, from February 2012 in yellow, from May 2012 in blue, and from July 2012 in green. Stress for these ordination are 0.10 (a) and 0.19 (b). 

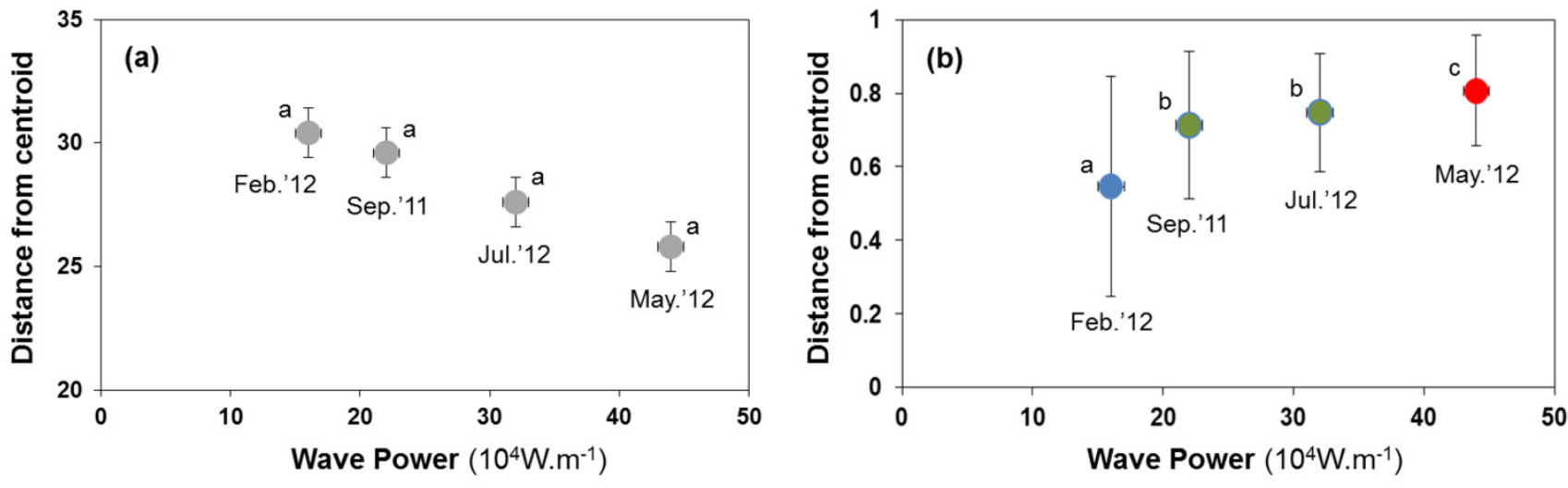

203

204 Fig. 4 Habitat heterogeneity (a) and $\beta$-diversity of macrobenthic assemblages (b) during four sampling events 205 associated with significant variation in wave energy preceding each event. Measure of habitat heterogeneity and $206 \beta$-diversity is the distance from centroids across all sites at a time. Letters and colours denote different groups $207 \quad(P<0.05)$ in permutational analysis of multivariate dispersion (PERMDISP). Error bars denote standard errors.

208

209

$210 \quad H 2$ : B-diversity declines after storms due to more homogenous sediment matrix.

211 Macrobenthic assemblages showed a significantly higher $\beta$ diversity following periods of higher wave

212 power (Fig. $3 b$ and $4 b$; PERMDISP $P=0.001$ ). Species that contributed most to differences in

213 macrobenthic assemblages among sampling periods are listed in Table 2 \& 3. Storm effects appear to be

214 driven mainly by large declines in the abundance of the tanaid Monokalliapseudes schubartti, whereas

215 polychaetes (i.e. Capitella sp.C, Heteromastus filiformis, Armandia hossfeldi) tended to increase in

216 abundance following storm events (Tables $2 \& 3$ ).

217

218 Table 2. Similarity percentage (SIMPER) analysis showing the contribution (\%) of the five most important species to 219 differences in species assemblages among sampling periods.

\begin{tabular}{lcccccc}
\hline & $\begin{array}{c}\text { Monokalliapseudes } \\
\text { Schubarti }\end{array}$ & $\begin{array}{c}\text { Capitella } \\
\text { sp. C }\end{array}$ & $\begin{array}{c}\text { Heteromastus } \\
\text { filiformis }\end{array}$ & $\begin{array}{c}\text { Scoloplos } \\
\text { sp1 }\end{array}$ & $\begin{array}{c}\text { Armandia } \\
\text { hossfeldi }\end{array}$ & $\begin{array}{c}\text { Mean } \\
\text { dissimilarity }\end{array}$ \\
\hline Sep vs. Feb & 10.98 & 4.96 & $\mathrm{n} / \mathrm{a}$ & 5.34 & $\mathrm{n} / \mathrm{a}$ & 68.1 \\
Sep vs. May & 11.14 & 6.55 & $\mathrm{n} / \mathrm{a}$ & 5.46 & $\mathrm{n} / \mathrm{a}$ & 74.9 \\
Sep vs. Jul & 9.65 & 6.85 & 5.51 & 5.27 & 6.47 & 69.3 \\
Feb vs. May & 16.03 & 8.17 & 5.04 & 5.44 & $\mathrm{n} / \mathrm{a}$ & 75.3 \\
Feb vs. Jul & 12.75 & 7.9 & 5.9 & 5.37 & 7.24 & 71.6 \\
May vs. Jul & 8.29 & 8.97 & 6.63 & 6.22 & 8.04 & 69.9 \\
\hline
\end{tabular}

220

221

222

223 
224 Table 3. Temporal variation in the density (ind. $\mathrm{m}^{-2}$ ) of species that accounted for most of the assemblage-wide 225 differences in macrobenthic assemblages among sampling events (cf. Table 2).

\begin{tabular}{|c|c|c|c|c|}
\hline & $\begin{array}{c}\text { September } \\
2011\end{array}$ & $\begin{array}{c}\text { February } \\
2012 \\
\end{array}$ & $\begin{array}{l}\text { May } \\
2012\end{array}$ & $\begin{array}{c}\text { July } \\
2012\end{array}$ \\
\hline & mean (se) & mean (se) & mean (se) & mean (se) \\
\hline Monokalliapseudes schubartii & $2151(635)$ & 3264 (571) & $1776(79)$ & $538(276)$ \\
\hline Capitella sp.C & $114(68)$ & $521(257)$ & $667(428)$ & $768(336)$ \\
\hline Heteromastus filiformis & $23(9)$ & $32(11)$ & $47(12)$ & $133(36)$ \\
\hline Scoloplos sp1 & $112(30)$ & $63(14)$ & $35(10)$ & 87 (19) \\
\hline Armandia hossfeldi & $50(25)$ & $7(4)$ & $47(19)$ & $224(74)$ \\
\hline
\end{tabular}

\section{6}

227

228 H3: Storm disturbance results in lower abundance, biomass, and species richness

229 Abundance, species richness and biomass were significantly lower in samples taken shortly after high-

230 energy wave events (Fig. 5). The mean number of species per site was lowest at 9.82 species after the

231 strongest wave event, compared with 11.82 to 14.35 species at other times (Fig. 5a). Abundance peaked

232 at 4126 ind. $\mathrm{m}^{-2}$ in Feb. 2012, declining to 1195 ind. $\mathrm{m}^{-2}$ after the storm in May 2012 (Fig. 5b). Biomass

233 declined from 6.5 to 3.5 gAFDW. ${ }^{-2}$ between September 2011 and May 2012 (Fig. 5c). 

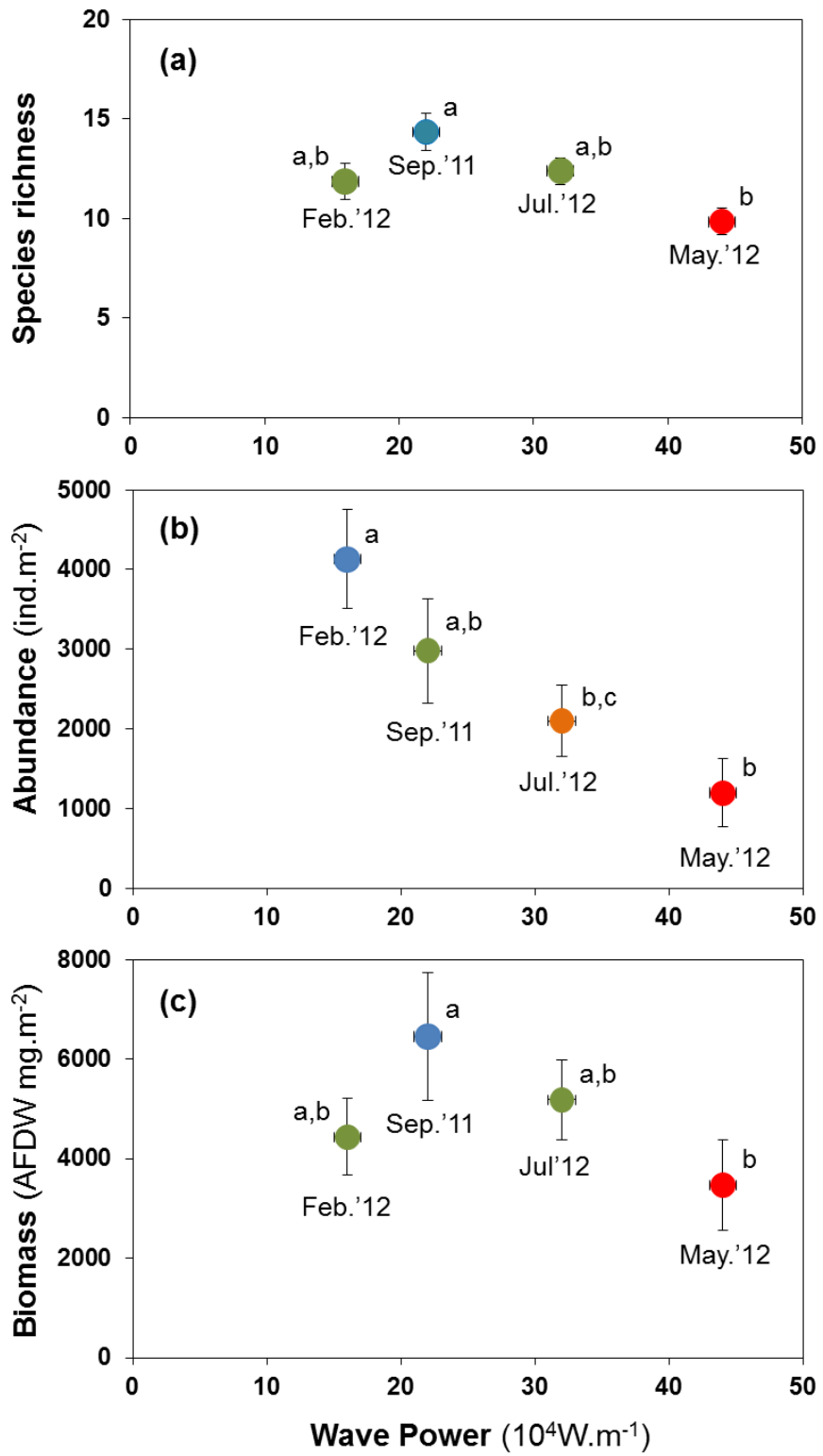

Fig. 5 Variation in the mean number of species per site (a), mean abundance (b) and mean biomass (c) of macrobenthic assemblages at four sampling events associated with significant variation in wave energy preceding each event. Letters and colours denote different groups in generalized linear models $(P<0.05)$. Error bars denote standard errors.

All major groups of intertidal macrofauna (i.e. molluscs, polychaetes, crustaceans) were affected by storms (Fig. 6). The mean number of species per site of all groups was significantly lower after the

242 strongest wave event $(P<0.05)($ Fig. $6 a-C)$. Temporal patterns of changes in abundance and biomass

243 did, however, differ between groups. Crustaceans showed the most pronounced density (Fig. 6f) and

244 biomass (Fig. 6i) response, declining strongly after storms. Molluscs showed a broadly similar density 
245 pattern to crustaceans, albeit being less pronounced (Figs. $6 \mathrm{~d} \& 6 \mathrm{~g}$ ), whereas the abundance of 246 polychaetes tended to increase following periods of higher wave energy (Figs. $6 e$ \& $6 \mathrm{~h}$ ).
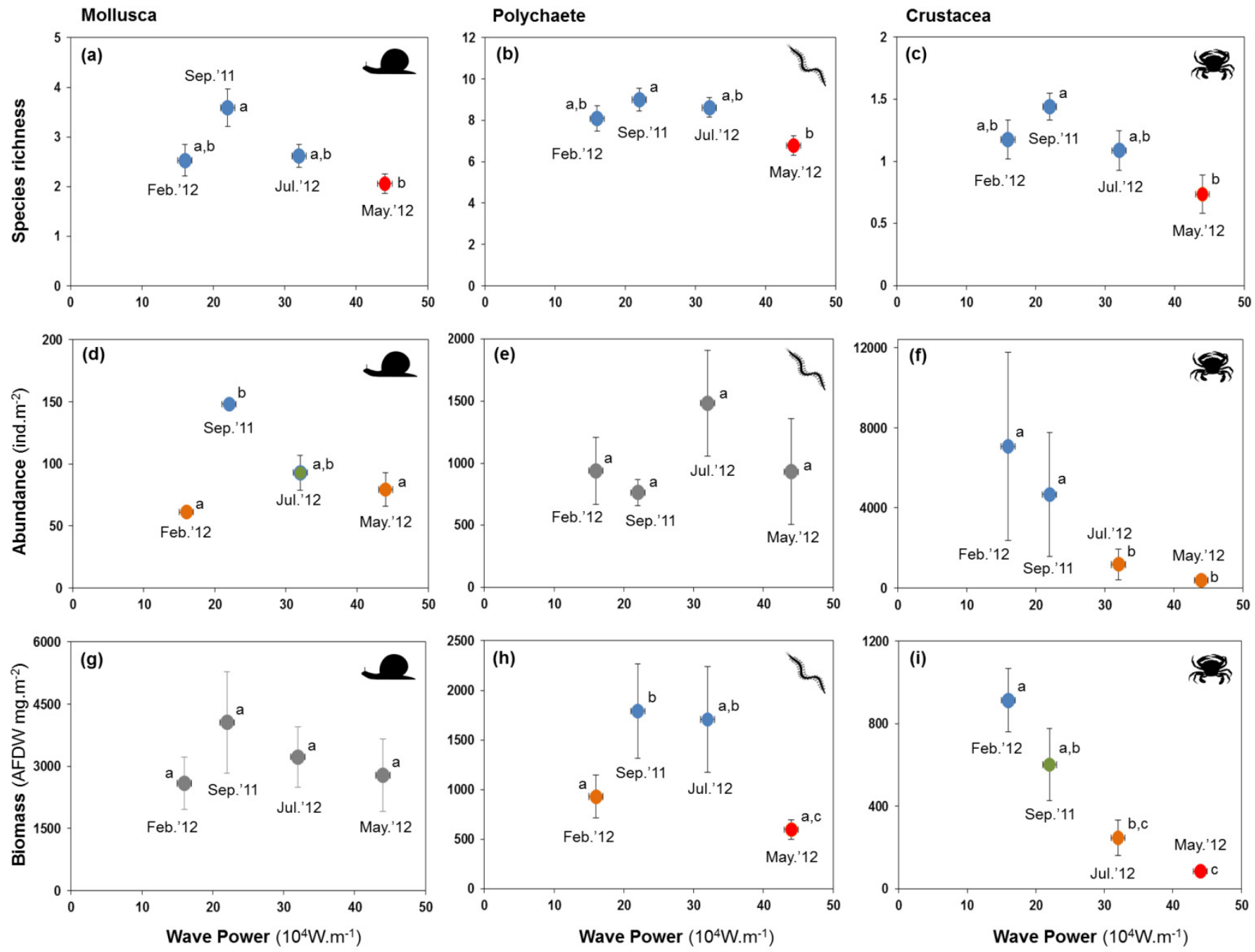

Fig. 6 Variation in the mean number of species, abundance, and biomass of molluscs (a, d \& g), polychaetes (b, e \& $h$ ), and crustaceans (c, $f \& i)$ at four sampling events associated with significant variation in wave energy preceding each event. Letters and colours denote different groups in generalized linear models $(P<0.05)$. Error bars denote standard errors.

H4: Species losses drive most of the change in $\beta$-diversity.

Declines in species numbers accounted for most of temporal $\beta$-diversity in the macrobenthos, and its contribution was higher shortly after storms (Table 4). By contrast, species replacement was less important. 


\section{2}

263

264

265

266

267

268

269

270

271

272

273

274

275

276

277

278

279

280

281

282

283

284

285

286

287

Table 4 - B-diversity and $\beta$-diversity partitioning among sampling periods. Higher values of $\beta$-diversity denote greater differences in the composition of species and number of individuals between two consecutive sampling times. Percentages indicate the amount of variation between periods attributable to species losses or species replacement.

\begin{tabular}{cccc}
\hline & Total $\boldsymbol{\beta}$ diversity $\left(\boldsymbol{\beta}_{\text {total }}\right)$ & $\begin{array}{c}\text { Species replacement / } \\
\text { substitution }\left(\boldsymbol{\beta}_{\text {repl }}\right)\end{array}$ & $\begin{array}{c}\text { Species loss / gain } \\
\text { richness differences }\left(\boldsymbol{\beta}_{\text {rich }}\right)\end{array}$ \\
\hline Sep. vs Feb. & 0.45 & $44.4 \%$ & $56.4 \%$ \\
Feb. vs May & 0.79 & $16.4 \%$ & $83.6 \%$ \\
May vs July & 0.47 & $11.7 \%$ & $89.3 \%$ \\
\hline mean & 0.57 & $24.2 \%$ & $76.4 \%$ \\
\hline
\end{tabular}

\section{Discussion}

Significant changes in macrobenthic species richness, abundance and biomass in a tropical tidal flat were associated with storms. This resulted in significant changes to fauna $\beta$-diversity over time that was mainly attributable to species losses, but not strongly linked to variation in habitat heterogeneity.

Previous studies about the influence of storms on coastal soft-sediment ecosystems have shown that storms may have stronger impacts on environmental features than on the fauna (e.g. Saloman and Naughton 1984, Cochôa et al. 2006, Alves and Pezzuto 2009, Harris et al. 2011), and that offshore sediment transport is the dominant geo-morphological response of sedimentary shores to increased wave energy (Masselink et al. 2016). These studies were, however, mostly done on exposed ocean beaches, habitats with fewer species that are well adapted to high-energy conditions (Brown 1996, Schlacher et al. 2008). By contrast, our results showed that under more sheltered conditions, storm impacts were more evident for the fauna than for the environment.

The observed decrease in the number of species, individuals and biomass of macrobenthic assemblages may have been caused by accretion and redistribution of sediments, burying fauna at some site and winnowing them from others. Waves and currents may suspend fine-grained sediments (Lohrer et al. 2006), and alongshore sediment distribution within the same system or accretion of sediment in washover deposit can occur after storms (Masselink et al. 2016). Moreover, Alcantará-Carrió et al. (2017) showed that the seaward transport of terrigenous sediment after intense rains in combination with resuspension of sediments by storm waves and transport by wind-driven currents alter the sedimentary features in the São Sebastião Channel. These hypothesized mechanisms of fauna change are functionally supported by studies showing significant changes to the macrobenthos following sediment deposition and substantial 
288

289

290

291

292

293

294

295

296

297

298

299

300

301

302

303

304

305

306

307

308

309

310

311

312

313

314

315

316

317

318

319

320

321

322

323

324

alterations in hydrodynamic regimes (Jaramillo et al. 2012, Cummings et al. 2003, Rodil et al. 2011, Schlacher et al. 2012).

Whilst storms were followed by decreases in species richness in all major groups of the macrobenthos, changes in species richness were more pronounced in crustaceans, which also declined strongly in abundance and biomass. This was mainly a consequence of massive (-95\%) declines of the tanaid Monokalliapseudes schubarti. M. schubarti is small (ca. $5 \mathrm{~mm}$ ) and builds tubes that rarely extend for more than $5 \mathrm{~cm}$ into the sediment, possibly making it more susceptible to sediment erosion (Nucci et al. 2001). In fact, morphological traits of benthic invertebrates have been suggested to modulate storms impacts (Mateo and Garcia-Rubies 2012), with small-bodied individuals and those with low mobility thought to be more susceptible to storms (Negrello Filho and Lana 2013, Urabe et al. 2013).

Fewer species of polychaetes were recorded at lower biomass after storm events. Some species, mostly small and tubiculous forms such as Isolda pulchella (Müller in Grube, 1858), were less numerous after storms. By contrast, opportunistic polychaete species (e.g. Capitella spp, Heteromastus filiformis (Pearson and Rosenberg 1978)) increased in abundance after storms. We did not reccord significant changes in the biomass of molluscs, possibly a consequence of heavier, shelled forms of the macrobenthos being less likely to be displaced by turbublent currents associated with storms.

The relationship between wave power and changes in macrobenthic fauna metrics approximated in several cases a bell-shaped curve, suggesting a resemblance with the "intermediate disturbance hypothesis" (IDH, Connel 1978); a core prediction of IDH is that at high disturbance levels species intolerant of the disturbance become locally extirpated whereas more intense competition limits species numbers at low disturbance intensity and frequency. Consequently, the highest number of species is expected to occur at intermediate levels of disturbance (but see Fox (2013), Sheil and Burslem (2013), and Huston (2014) for discussions on the validity of the IDH). Arguably, disturbance by wave energy at intermediate levels may have enhanced species richness and productivity at sedimentary coastal ecosystem by reducing competition. Nevertheless, as pointed out by Huston (2014), the causes of high diversity go beyond the simple effects of disturbances slowing the process of competitive exclusion and must include multiple ecological and evolutionary processes. In sedimentary shorelines, especially in sheltered environments, intermediate disturbance caused by waves is expected to increase water circulation processes and may also enhance biodiversity and productivity of macrobenthic assemblages by increasing the amount of food available in the water column, and/or reducing the concentration of nutrients in the sediment, resulting in lower eutrophication processes (Cloern 2001, Corte et al. 2017).

Storm effects appeared to be influenced by the timing of a storm in relation to the tidal regime. Masselink et al. (2016) found that storms impacts on the south-west coast of England were highest when the peak 
325

326

327

328

329

330

331

332

333

334

335

336

337

338

339

340

341

342

343

344

345

346

347

348

349

350

351

352

353

354

355

356

357

358

storm waves coincided with spring high tides. In our study, this was likely the case in May 2012 when the height of the storm passed during a spring tide. The observed effects of storms on the macrobenthic fauna of Araçá Bay also appeared to be stronger during a short time after storms. We found that differences in environmental and biotic characteristics were most pronounced in May 2012, when samples were taken one day after the storm had passed.

Most species typical of sedimentary shorelines are, to some degree, adapted to high-energy conditions and hence may recover relatively quickly (e.g. within days to weeks) from most storm events (Harris et al. 2011, Schlacher and Thompson 2013; Machado et al. 2016). For example, in a subtropical coastal softsediment ecosystem in South Brazil, Gallucci and Netto (2004) found that abundance and number of species of macrobenthic organisms declined during the passage of a cold front, but all values were back to pre-frontal conditions within a day. Similarly, Machado et al. (2016) found recovery of macrobenthic assemblages inhabiting tropical ocean exposed beaches within seven weeks of a storm. It is important to emphasize, however, that recovery depends on the magnitude, spatial scale and return frequency of the disturbance events in soft-sediment environments and other marine systems (Lucrezi et al. 2010, Urabe et al. 2013, McClain and Schlacher 2015, Schlacher et al. 2015). The most powerful storms may cause ecological changes that require years to recover and may compromise the spatial and trophic structure of the ecosystems (Jaramillo et al. 1987, Mateo and Garcia-Rubies 2012).

\section{Conclusion}

Here we show that storms can cause significant changes to macrobenthic assemblages inhabiting a tidal flat. Decreases in species richness, abundance, and biomass of invertebrate assemblages were related to increases in wave power. Species losses drove changes towards higher $\beta$-diversity, but the fauna appeared to recover within a few weeks. Changes in habitat features were comparatively smaller. Given that storm activity, location and intensity are predicted to change over the coming decades in a warming world (Lin and Emanuel 2016, Walsh et al. 2016), ecological changes attributed to altered storm properties are likely. Unfortunately, the functional consequences of altered storm regimes for coastal ecosystems are largely unknown, including the continued provision of ecosystem services such as coastal protection and capture fisheries. Thus, future work shall prioritise investigations of how ecological processes in coastal ecosystems respond to extreme events and which features may determine their resilience and recovery.

\section{Acknowledgements}


359 We thank Elizabeth Eddy, Daniel Martin, Paulo Paiva, André Garraffoni, Maikon Di Domenico, David 360 Schoeman, and Ronaldo Christofoletti for comments and suggestions. We are also grateful to two

361 anonymous referees that provided very constructive comments on the manuscript. Special thanks to 362 Angélica Godoy, Camila Silva, Nathalia Padovanni, Rachel Daolio, Décio Filho, and Renata Alitto who 363 helped with field work and species identifications.

\section{References}

Alcántara-Carrió J, Sasaki DK, de Mahique MM, Taborda R, and de Souza LAP (2017) Sedimentary constraints on the development of a narrow deep strait (São Sebastião Channel, SE Brazil). Geo-Marine Letters, 1-14.

Alves ES, and Pezzuto PR (2009) Effect of cold fronts on the benthic macrofauna of exposed sandy beaches with contrasting morphodynamics. Brazilian Journal of Oceanography 57:73-94.

Amaral, A. C. Z., A. E. Migotto, A. Turra \& Y. Schaeffer-Novelli, 2010. Araçá: biodiversidade, impactos e ameaças.

371 Biota Neotropica 10: 219-264.

372 Anderson MJ (2006) Distance-based tests for homogeneity of multivariate dispersions. Biometrics 62:245-253.

373

374

375

376

377

378

379

380

381

382

383

384

385

386

387

Anderson, M. J., Ellingsen, K. E., \& McArdle, B. H. (2006). Multivariate dispersion as a measure of beta diversity. Ecology letters, 9: 683-693.

Anderson MJ, Crist TO, Chase JM, Vellend M, Inouye BD, Freestone AL, Sanders NJ, Cornell HV, Comita LS, Davies KF, Harrison SP (2011) Navigating the multiple meanings of $\beta$ diversity: a roadmap for the practicing ecologist. Ecology letters 14:19-28.

Brown AC (1996) Behavioural plasticity as a key factor in the survival and evolution of the macrofauna on exposed sandy beaches. Revista Chilena de Historia Natural 69:469-474.

Camargo MG (2006) Sysgran: um sistema de código aberto para análises granulométricas do sedimento. Revista Brasileira de Geociências 36: 371-378.

Cardoso P, Rigal F, and Carvalho JC (2015) BAT - Biodiversity Assessment Tools, an R package for the measurement and estimation of alpha and beta taxon, phylogenetic and functional diversity. Methods in Ecology and Evolution 6:232-236.

Carvalho JC, Cardoso P, and Gomes P (2012) Determining the relative roles of species replacement and species richness differences in generating beta-diversity patterns. Global Ecology and Biogeography 21:760-771.

Clarke KR, Gorley RN (2006) PRIMER V6: user manual-tutorial. Plymouth Marine Laboratory

Cloern, JE (2001) Our evolving conceptual model of the coastal eutrophication problem. Marine Ecology Progress Series 210: 223-253

Cochôa AR, Lorenzi I, and Borzone aCAA (2006) A Influência da Passagem de uma Frente Meteorológica na Distribuição da Macrofauna Bentônica Mesolitoral de uma Praia Arenosa Exposta. Tropical Oceanography 34:59-71.

Connell, J. H. 1978. Diversity in tropical rain forests and coral reefs. Science 199:1302-1310.

Corte GN, Coleman RA, Amaral AC (2017) Environmental influence on population dynamics of the bivalve Anomalocardia brasiliana. Estuarine, Coastal and Shelf Science 187:241-8.

Cummings V, Thrush S, Hewitt J, Norkko A, and Pickmere S (2003) Terrestrial deposits on intertidal sandflats: Sediment characteristics as indicators of habitat suitability for recolonising macrofauna. Marine Ecology Progress Series 253:39-54. 
398 Dottori M, Siegle E, and Castro BM (2015). Hydrodynamics and water properties at the entrance of Araçá Bay,

399 Brazil. Ocean Dynamics 65: 1731-1741.

400 Fo C (1990) Wind driven currents in the Channel of São Sebastião: winter, 1979. Boletim do Instituto Oceanográfico

401 38:111-132.

402 Folk,RL and Ward WC (1957) Brazos River Bar: a study in the significance of grain-size parameters. Journal of 403 Sedimentary Petrology 27: 3-26.

404 Fox, J. W. 2013. The intermediate disturbance hypothesis should be abandoned. Trends in Ecology and Evolution $405 \quad 28: 86-92$

406 Gallucci F, and Netto SA (2004) Effects of the passage of cold fronts over a coastal site: An ecosystem approach. 407 Marine Ecology Progress Series 281:79-92.

408 Gattuso JP, Magnan A, Billé R, Cheung WWL, Howes EL, Joos F, Allemand D, Bopp L, Cooley SR, Eakin CM, 409 Hoegh-Guldberg O, Kelly RP, Pörtner HO, Rogers AD, Baxter JM, Laffoley D, Osborn D, Rankovic A, Rochette J, 410 Sumaila UR, Treyer S, and Turley C (2015) Contrasting futures for ocean and society from different anthropogenic 411 CO2 emissions scenarios. Science 349.

412 Harris L, Nel R, Smale M, and Schoeman D (2011) Swashed away? Storm impacts on sandy beach macrofaunal 413 communities. Estuarine Coastal and Shelf Science 94:210-221.

414 Hauser DDW, Tobin ED, Feifel KM, Shah V, and Pietri DM (2016) Disciplinary reporting affects the interpretation of 415 climate change impacts in global oceans. Global Change Biology 22:25-43.

416 Herbich JB (2000) Handbook of coastal engineering. McGraw-Hill, New York

417 Huston MA (2014). Disturbance, productivity, and species diversity: empiricism vs. logic in ecological

418 theory. Ecology, 95:2382-2396.

419

420

421

422

423

424

425

426

427

428

429

430

431

432

433

434

435

436

IPCC (2013) Climate Change 2013: The Physical Science Basis. Contribution of Working Group I to the Fifth Assessment Report of the Intergovernmental Panel on Climate Change. [Stocker, T.F., D. Qin, G.-K. Plattner, M. Tignor, S.K. Allen, J. Boschung, A. Nauels, Y. Xia, V. Bex and P.M. Midgley (eds.)]. Cambridge University Press, Cambridge, UK

Jaramillo E, Croker RA, and Hatfield EB (1987) Long-term structure, disturbance, and recolonization of macroinfauna in a New Hampshire sand beach. Canadian Journal of Zoology 65:3024-3031.

Jaramillo E, Dugan JE, Hubbard DM, Melnick D, Manzano M, Duarte C, Campos C, and Sanchez R (2012) Ecological implications of extreme events: Footprints of the 2010 earthquake along the Chilean coast. PLoS ONE 7:e35348. doi:35310.31371/journal.pone.0035348.

Legendre P, Cáceres $\mathrm{M}$. Beta diversity as the variance of community data: dissimilarity coefficients and partitioning. Ecology Letters. 2013 Aug 1;16(8):951-63.

Lin N, and Emanuel K (2016) Grey swan tropical cyclones. Nature Climate Change 6:106-111.

Lohrer A M, Hewitt JE, and Thrush SF (2006). Assessing far-field effects of terrigenous sediment loading in the coastal marine environment. Marine Ecology Progress Series 315:13-18.

Lucrezi S, Schlacher TA, and Robinson W (2010) Can storms and shore armouring exert additive effects on sandybeach habitats and biota? Marine and Freshwater Research 61:951-962.

Machado PM, Costa LL, Suciu MC, Tavares DC, and Zalmon IR (2016) Extreme storm wave influence on sandy beach macrofauna with distinct human pressures. Marine Pollution Bulletin. 
437 Masselink G, Scott T, Poate T, Russell P, Davidson M, and Conley D (2016) The extreme 2013/2014 winter storms:

438 Hydrodynamic forcing and coastal response along the southwest coast of England. Earth Surface Processes and

439 Landforms 41:378-391.

440 Mateo MA and Garcia-Rubies T (2012). Assessment of the ecological impact of the extreme storm of Sant Esteve's 441 Day (26 December 2008) on the littoral ecosystems of the north Mediterranean Spanish coasts. Final Report (PIEC

442 200430E599).

443 McClain CR, Barry JP (2010) Habitat heterogeneity, disturbance, and productivity work in concert to regulate 444 biodiversity in deep submarine canyons. Ecology 91:964-76.

445 McClain CR, and Schlacher TA (2015) On some hypotheses of diversity of animal life at great depths on the sea 446 floor. Marine Ecology 36:849-872.

447 Meager J, Schlacher TA, and Green M (2011) Topographic complexity and landscape temperature patterns create a 448 dynamic habitat structure on a rocky intertidal shore. Marine Ecology Progress Series 428:1-12.

449 Nagelkerken I, and Munday PL (2016) Animal behaviour shapes the ecological effects of ocean acidification and 450 warming: Moving from individual to community-level responses. Global Change Biology 22:974-989.

451 Negrello Filho OA, and Lana PC (2013) Short-term stability of estuarine benthic assemblages: Are storms pattern452 defining events? Zoologia 30:266-272.

453 Nucci PR, Turra A., and Morgado EH (2001) Diversity and distribution of crustaceans from 13 sheltered sandy 454 beaches along Sao Sebastiao Channel, south-eastern Brazil. Journal of the Marine Biological Association of the 455 United Kingdom 81:475-484.

456 Oksanen J, Kindt R, Legendre P, O’Hara B, Stevens MH, Oksanen MJ, Suggests MA (2007) The vegan package.

457 Community ecology package.

458 Pianca C, Mazzini PL, Siegle E (2010) Brazilian offshore wave climate based on NWW3 reanalysis. Brazilian Journal 459 of Oceanography 58:53-70

460 Podani J, and Schmera D (2011) A new conceptual and methodological framework for exploring and explaining 461 pattern in presence - absence data. Oikos 120:1625-1638.

462 Posey M, Lindberg W, Alphin T, and Vose F (1996) Influence of storm disturbance on an offshore benthic community. 463 Bulletin of Marine Science 59:523-529.

464 Ripley B, Venables B, Bates DM, Hornik K, Gebhardt A, Firth D, Ripley MB (2013) Package 'MASS'. Cran R.

465 Rodil IF, Lohrer AM, Chiaroni LD, Hewitt JE, and Thrush SF (2011) Disturbance of sandflats by thin terrigenous

466 sediment deposits: Consequences for primary production and nutrient cycling. Ecological Applications 21:416-426.

467 Saloman $\mathrm{CH}$, and Naughton SP (1984) Beach restoration with offshore dredged sand: effects on nearshore macroinfauna. NOOA Technical Memorandum NMFS-SEFC-133

469

Schlacher TA, and Thompson L (2013) Environmental control of community organisation on ocean-exposed sandy beaches. Marine and Freshwater Research 64:119-129.

471 Schlacher TA, Schoeman DS, Dugan JE, Lastra M, Jones A, Scapini F, and McLachlan A (2008) Sandy beach

472 ecosystems: key features, sampling issues, management challenges and climate change impacts. Marine Ecology 29 473 (S1):70-90.Schlacher TA, Noriega R, Jones A, and Dye T (2012) The effects of beach nourishment on benthic 474 invertebrates in eastern Australia: Impacts and variable recovery. Science of the Total Environment 435:411-417.

475 Schlacher TA, Weston MA, Schoeman DS, Olds AD, Huijbers CM, and Connolly RM (2015) Golden opportunities: A 476 horizon scan to expand sandy beach ecology. Estuarine, Coastal and Shelf Science 157:1-6. 
477 Sheil D, Burslem DF (2013) Defining and defending Connell's intermediate disturbance hypothesis: a response to 478 Fox. Trends in Ecology and Evolution 28:571-2.

479 Turra A, Pombo M, Petracco M, Siegle E, Fonseca M, Denadai MR (2016) Frequency, Magnitude, and Possible 480 Causes of Stranding and Mass-Mortality Events of the Beach Clam Tivela mactroides (Bivalvia: Veneridae). PLoS 481 ONE 11(1): e0146323. doi:10.1371/journal.pone.0146323

482 Urabe J, Suzuki T, Nishita T, and Makino W (2013) Immediate Ecological Impacts of the 2011 Tohoku Earthquake 483 Tsunami on Intertidal Flat Communities. PLOS ONE 8.

484 Walsh KJE, McBride JL, Klotzbach PJ, Balachandran S, Camargo SJ, Holland G, Knutson TR, Kossin JP, Lee Tc, 485 Sobel A, and Sugi M (2016) Tropical cyclones and climate change. Wiley Interdisciplinary Reviews: Climate Change 486 7:65-89.

487 Weatherdon LV, Magnan AK, Rogers AD, Sumaila UR, and Cheung WWL (2016) Observed and projected impacts of 488 climate change on marine fisheries, aquaculture, coastal tourism, and human health: An update. Frontiers in Marine 489 Science 3.

490

491 